\title{
Pediculated Intercostal Muscle Flaps in Bronchiactasis Resectional Surgery for Bronchial Stump Reinforcement
}

\author{
Farhan Ahmed Majeed1, Ahmed Raza2, Tashfeen Imtiaz³ and Kamran Rahim \\ IDepartment of Thoracic Surgery, Combined Military Hospital, Lahore, Pakistan \\ ${ }^{2}$ Department of Thoracic Surgery, Combined Military Hospital, Multan, Pakistan \\ ${ }^{3}$ Department of Thoracic Surgery, Pakistan Institute of Medical Sciences (PIMS), Islamabad, Pakistan \\ ${ }^{4}$ Department of Thoracic Surgery, Combined Military Hospital, Kharian, Pakistan
}

\begin{abstract}
Objective: To determine the outcome of muscle flap to cover the bronchial stump in the resectional surgery for bronchiectasis for prevention of bronchopleural fistula.

Study Design: Case series.

Place and Duration of Study: Combined Military Hospitals of Quetta, Lahore, and Rawalpindi from January 2006 to August 2017.

Methodology: Patients with localised bronchiectatic changes were included. Patients with carcinoma and without flap resection were excluded. Resectional surgery was performed through posterolateral thoracotomy approach, under general anesthesia with one lung ventilation. Pediculated or bipediculated intercostal muscle flap (ICM) was used to reinforce the bronchial stump. Pediculated ICM flaps were utilised for reinforcement of bronchial stump and bipediculated flaps were used over lesser.

Results: Three hundred and ninety-eight cases of bronchiectasis with average age of patients $38.5 \pm 19.8$ years and male to female ratio of 2:1 were included. Bronchiectasis was unilateral in 377 cases. Tuberculous was found in 278 of the cases. Thirty-five had poor lung function tests (FEV1 <1.5\%). Eighty-two patients underwent pneumonectomy, 228 patients had lobectomy and 88 patients underwent segmentectomy. Posterior-based pediculated ICM flap was used in 365 patients, and bipediculated ICM flaps in 30 cases. The most common complication was post-thoracotomy neuralgia 53. Bronchopleural fistula, despite transposition of intercostal muscle flap on bronchial stump, was present in 4 patients.

Conclusion: Application of muscle flap over bronchial stump after resection surgery for bronchiectasis, is simple, safe and effective surgical option to avoid complication of bronchopleural fistula.
\end{abstract}

Key Words: Bronchopleural fistula, Bronchiectasis, Intercostal muscle flap, Tuberculosis bronchial stump reinforcement.

How to cite this article: Majeed FA, Raza A, Imtiaz T, Rahim K. Pediculated intercostal muscle flaps in bronchiactasis resectional surgery for bronchial stump reinforcement. J Coll Physicians Surg Pak 2020; 30(2):197-200.

\section{INTRODUCTION}

Bronchiectasis is defined as an abnormal and permanent dilatations of bronchi with destruction of the bronchial wall, as consequence of inflammation and destruction of the structural components. The goals of surgical therapy are to improve symptoms, to reduce complications, to control exacerbations, and to reduce morbidity and mortality. Pulmonary resection for bronchiectasis can be done with low mortality and morbidity. When possible, complete resection should be performed. ${ }^{1}$

The prevalence of bronchiectasis has declined in developed countries with improved healthcare and the

Correspondence to: Dr. Farhan Ahmed Majeed, Department of Thoracic Surgery, Combined Military Hospital, Lahore,

Pakistan

E-mail:famajeed@yahoo.com

Received: June 02, 2018; Revised: May 25, 2019;

Accepted: August 26, 2019 availability of suitable antibiotics. ${ }^{2}$ It continues to be an important problem in developing countries because of increased prevalence of tuberculosis, pneumonia and other infections. Surgery may be considered to remove part of a lung where infection cannot be controlled or where excessive bleeding cannot be managed. Early recognition and adequate treatment can help control bronchiectasis and decrease symptoms. In a series of 166 patients who underwent pneumonectomy, the indication in 158 was bronchiectasis with failure of medical treatment. 3

The decision and preparation for surgery should be in cooperation with radiologist and the anatomy should be mapped clearly and the diseased part well localised. Both chest physician and the anesthetist must be involved early. Certain precaution is needed to avoid serious complication during the course of surgery, like the use of bronchus blocker such as a Fogarty catheter or using double lumen intubations to avoid spillage of secretions to the healthy lung. Careful isolation of the healthy lobe or the healthy other lung is crucial. The 


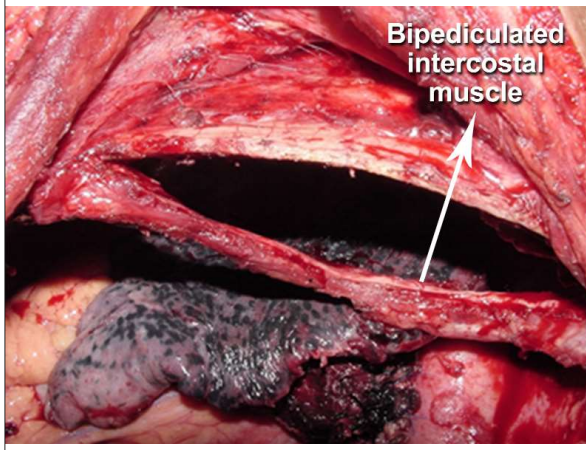

Figure 1: Bipediculated intercostal muscle flap harvesting.

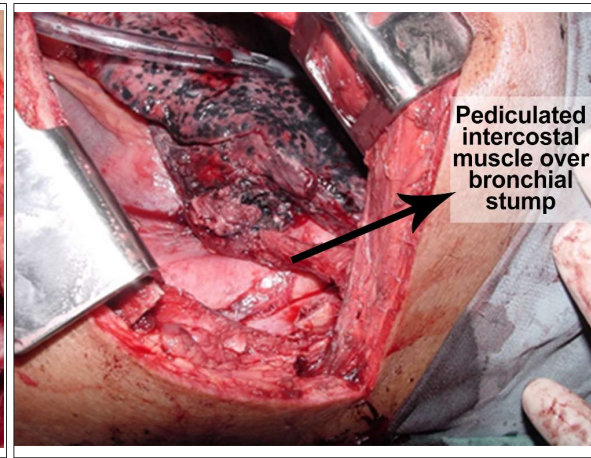

Figure 2: Pediculated muscle flap reinforcing bronchial stump.

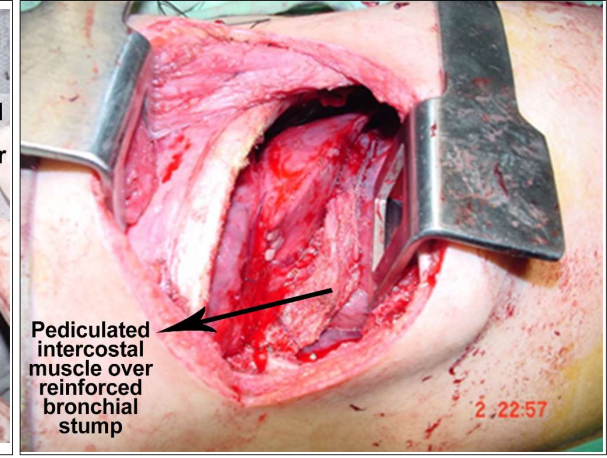

Figure 3: Pediculated intercostal muscle finally over bronchial stump. morbidity and mortality rates of bronchiectasis surgery are within acceptable ranges. Most of the patients benefit from surgery, especially when total excision is accomplished. The outlook depends upon the underlying reason for developing bronchiectasis. Congenital causes of bronchiectasis, like cystic fibrosis, may have a worse prognosis than acquired diseases.

Lung resection surgery may be considered in patients with localised disease with structural changes in whom symptoms are not controlled by medical treatment.

This study was carried out to determine the outcome of pediculated intercostal muscle flap to reinforce the bronchial stump in the resectional surgery for bronchiectasis.

\section{METHODOLOGY}

This retrospective study was conducted at Combined Military Hospitals of Quetta, Lahore, and Rawalpindi from January 2006 to August 2017. Ethical Committee approval was obtained. All the patients of bronchiectasis, irrespective of age and gender, who underwent resectional surgery, were included in the study. Patients of bronchiectasis that had been managed medically were excluded.

In total, 398 patients were included in the study through non-probability consecutive sampling. Resectional surgery was advised to these patients. Patients' particulars, age, gender, presenting signs and symptoms like pain, cough, hemoptysis, endobronchial symptoms were recorded. Associated problems, like weight loss and loss of appetite were also noted. Diagnosis was made on the basis of history and clinical and radiological assessment. CT scan chest was done in all cases to ascertain the site and degree of disease. Preoperative lung function tests were performed in these patients. Broad spectrum antibiotics were started in all the patients on admission. Blood complete picture, grouping and cross-match, coagulation profile, blood sugar, renal function tests, echocardiography, lung function tests, ECG, and x-ray chest were advised before surgery.

All the resections were performed under general anesthesia with one lung ventilation. In case of a bilateral disease, more effected side was operated first. Chest was opened via posterolateral thoracotomy incision. Bipediculated or pediculated intercostal muscle flap was used to reinforce the bronchial stump. Bipediculated flaps were used over lesser resections to cover larger areas; and pediculated ICM flaps were utilised for reinforcement of bronchial stump. Bronchial resection was closed by linear reload stapler.

In technique of intercostal muscle (ICM) harvesting, the periosteum was mobilised at place of retractor to avoid pressure; but harvesting was fine after completion of procedure. Intercostal muscle flap was harvested on the basis of both anterior and posterior intercostal arteries in case of bipediculated intercostal muscle flap (Figure 1); and in case of pediculated muscle flap, it was based on posterior intercostal artery (Figure 2). In case of pediculated ICM flap, good length of ICM was dissected away from the upper border of lower rib; and after applying clamp at anterior end, the muscle was severed by sharp dissection; and remnant anterior end of ICM was transfixed with silk 1 , to achieve permanent hemostasis. Health of flap was judged by good bleeding from the cut edge. Interposition of intercostal muscle flap was used to minimise bronchopleural fistula after strengthening the bronchial edges with prolene $3 / 0$ (Figure 3). Great care was taken to avoid any stretch or rotation on the flap. While applying prolene $3 / 0$ between flap and the bronchial stump, vascular supply was saved and no needle prick in bronchial stump was made distal to staple line. Care was taken to avoid any double or missed prick in bronchial stump. Air leak and hemostasis were checked before closure.

Postoperatively patients were kept in high dependency unit and encouraged by incentive spirometer. Postoperatively, all the patients were closely monitored regarding the state residual lung expansion. Chest physiotherapy, antibiotics, early mobilisation out of bed continued postoperatively for 3 to 4 days, followed by resectional surgery. Hospital stay ranged from 4 to 14 days. At the time of discharge, the patients were advised to follow-up in thoracic surgery outpatient department after one week and then at second week. On follow-up, the post thoracotomy neuralgia, lung expansion, and wound healing were recorded and advised to continue 
follow-up initially after one month for three months, and then after every three months. Data was analyzed using SPSS version 22. Descriptive statistics were used to describe the results, i.e. mean and standard deviation for quantitative variables; while frequency and percentages for qualitative variables.

\section{RESULTS}

Three hundred and ninety-eight cases of bronchiectasis with average age of patients 38.5, with SD 19.8 years, and male to female ratio of $2: 1$, were included. Bronchiectasis was unilaterally occurred in 377 (94.8\%) cases. Presenting complaints were productive cough $(n=398) 100 \%$, hemoptysis $(n=282) 70.9 \%$, chest pain $(n=191) 48.1 \%$, weight loss $(n=62) 15.5 \%$ and loss of appetite $(n=49) 12.4 \%$. Tuberculous disease was found in $70 \%(n=278)$ of cases. Thirty-five $(8.9 \%)$ had poor lung function tests (FEV1 $<1.5 \%)$.

Eighty-two (20.6\%) patients underwent pneumonectomy, $228(57.2 \%)$ patients had lobectomy, and $88(22.1 \%)$ patients underwent segmentectomy. Left upper lobe was the most affected in $64(16.08 \%)$ cases. Posterior based pediculated ICM flap was in 365 patients, bipediculated ICM flaps were in 30 cases, and anterior based pediculated ICM flaps in four cases. Common complication was post-thoracotomy neuralgia $(n=53)$ $13.4 \%$ and wound infection $(n=9) 2.4$. Broncho-pleural fistula, despite transposition of intercostal muscle flap on bronchial stump, was present in $1 \%(n=4)$ of patients.

\section{DISCUSSION}

Destroyed lung is described as nonfunctional lung and is most often caused by inflammatory diseases. Surgical resection is used to resolve or prevent complications and improve quality of life. ${ }^{4}$ Bronchopleural fistula is one of the most dangerous complications, and a common problem following procedures, like pneumonectomy, lobectomy or any other kind of resectional surgery. ${ }^{5}$ For the thoracic surgeon, a BPF specifically refers to a breakdown of the bronchial stump after surgery. The incidence of postoperative BPF is thankfully low, ${ }^{6}$ but it can quickly lead to a pleural space infection with a high rate of mortality. Once a BPF occurs, it is difficult to treat, and may require very radical, debilitating thoracoplasty, muscle flap procedures or prolonged pleural space decontamination strategies. ${ }^{7}$ Factors associated with bronchopleural fistula are identified as pneumonectomy, long bronchial stump, pneumonia, radiation therapy, stapled bronchial closure, prolonged mechanical ventilation recurrent carcinoma, and tuberculosis. ${ }^{8}$

TB patients are at particular risk for BPF, given their often poor nutritional status at the time of surgery and the usually already inflamed/infected bronchi. Endobronchial TB, in particular, has been identified as a risk factor for development of BPF. 9 There have, therefore, been calls for careful preoperative bronchoscopic assessments or even on-table frozen section analysis of bronchial margins to exclude endobronchial TB, especially in cases of MDR-TB. 10

There is high incidence of bronchopleural fistula, approximately $25 \%$, following completion of right pneumonectomy for mycobacterial disease. This is lowered by muscle flaps. ${ }^{11}$ In another series, Giorgio Zanotti and coworkers found that the reported mortality rate exceeds $10 \%$, even if the patient survives, the recurrence rate of infection can be as high as $38 \%$. Importantly, up to $80 \%$ of cases of procedure related empyemas are associated with bronchopleural fistula; and fewer than $20 \%$ of these can be expected to close spontaneously. 12 Most surgeons would attempt to reduce the risk of BPF by covering the bronchial stump with a flap. Such flaps may be fashioned from pericardial fat, from pleura or pericardium, or from pediculated muscles, including pediculated intercostal muscle flaps or latissimus dorsi muscle flaps. This highlights the need for good nutrition prior to surgery in order to maintain healthy viable muscle flaps become necessary. ${ }^{13}$ Pneumonectomy is seldom indicated in the pediatric population. Resectional surgeries for inflam-matory lung disease are frequently associated with high mortality rates. The frequencies of post-pneumonectomy space empyema and bronchopleural fistula are high. ${ }^{4}$ Bronchopleural fistula after pneumonectomy has a wide range of reported occurrence (5 to $20 \%$ ) and is more commonly reported after induction treatment and on the right side. 14 The incidence of bronchopleural fistula after pulmonary resection is $1.2 \%-4.4 \% .15,16$

The aim of this study was to evaluate the efficacy and safety of using bipedicled or pediculated intercostal muscle flaps with blood supply to buttress the bronchial stump after resectional surgeries for bronchiectasis as a prophylactic technique. The mean follow-up period was six months. All patients remained symptom-free with no evidence of late bronchopleural fistula. ${ }^{17}$ This effort explains the need of continuous evolution of resectional surgery for bronchiectasis and related entities; and defines the current role of resectional surgery in bronchiectasis, multidrug-resistant tuberculosis, and fungal disease. It outlines the factors important in care of these patients, emphasising drug therapy, nutrition, and other factors for a successful outcome. Resectional surgery, most often, is accompanied by muscle transfers, which have for the most part replaced thoracoplasty. ${ }^{18}$

Coverage of bronchial stump after resectional surgery in fungal diseases is the need of time to avoid BPF. The operative treatment is to remove the aspergilloma by performing an extrapleural lobectomy with avoidance of pleural contamination, residual space to be obliterated, and to prevent bronchopleural fistulae. Presently, the authors used muscle transposition in all patients undergoing resection of complex aspergilloma. The transferred intercostal muscle is used to cover the bronchial stump. Postoperative morbidity and mortality is 
associated with resection of complex aspergilloma results from the underlying lung disease, intraoperative hemorrhage, prolonged air leaks, and incomplete reexpansion of the remaining lung with postoperative space complications. Unfortunately, little can be done to improve the patient's underlying lung function. The routine transposition of pedicled muscle flaps addresses both the problem of prolonged air leaks and residual pleural space.19 With good selection of patients, meticulous surgical techniques and good postoperative management, aggressive surgical treatment with antifungal therapy for pulmonary aspergilloma is safe and effective, and can achieve favourable outcomes. ${ }^{20}$ Compared with other methods of treating bronchopleural muscle grafting carried a higher rate of successful fistula closure and a lower mortality rate. 21

\section{CONCLUSION}

Intercostal muscle flap is a versatile flap. Intercostal muscle flaps with blood supply buttressing the bronchial stump is new prophylactic technique for BPF after resectional surgeries for patients with bronchiectasis. This is a simple, safe, and effective surgical option to avoid dreadful complication like bronchopleural fistula.

\section{ETHICAL APPROVAL:}

Ethical Committee of Combined Military Hospital, Lahore approved the study prior to initiation of the research work.

\section{PATIENTS' CONSENT:}

Informed consents were obtained from the patients to publish the data concerning this research work.

\section{CONFLICT OF INTEREST:}

Authors declared no conflict of interest.

\section{AUTHORS' CONTRIBUTION:}

FAM: Data collection, abstract writing and proofreading. AR: Introduction, discussion writing.

TI: Pictures and statistical analysis.

KR: References.

\section{REFERENCES}

1. Agasthian T, Deschamps C, Trastek V. Surgical management of bronchiectasis. Ann Thorac Surg 1996; 62:976-80.

2. Säynäjäkangas T, Keistinen T. Tuuponen SL. Bronchiectasis in Finland: Trends in hospital treatment. Respir Med 1997; 91: 395-8.

3. Kutlay $\mathrm{H}$, Cangir AK, Enön $\mathrm{S}$, Sahin $\mathrm{E}$, Akal M, Güngör A, et al. Surgical treatment in bronchiectasis: Analysis of 166 patients. Eur J Cardiothorac Surg 2002; 21:634-7

4. Kosar A, Orki A, Kiral H, Demirhan R, Arman B. Pneumonectomy in children for destroyed lung: Evaluation of 18 cases. Ann Thorac Sur 2010; 50:226.
5. Shah SA, Bilal A, Ahmed Z, Watson D. Post-pneumonectomy bronchopleural fistulae. J Postgrad Med Inst 2011; 11:1.

6. Naidoo R. Active pulmonary tuberculosis: Experience with resection in 106 cases. Asian Cardiovasc Thorac Ann 2007; 15:134-8.

7. Chan ECK, Lee TW, Ng CSH, Wan IYP, Sihoe ADL. Closure of postpneumonectomy bronchopleural fistula by means of single, perforator-based, latissimus dorsi muscle flap. J Thorac Cardiovasc Surg 2002; 124:1235-6.

8. Puskas JD, Mathisen DJ, Grillo HC, Wain JC, Wright CD, Moncure AC. Treatment strategies for broncho-pleural fistula. J Thorac Cardiovasc Surg 1995; 109:989-96.

9. Wang $\mathrm{H}$, Lin $\mathrm{H}$, Jiang $\mathrm{G}$. Pulmonary resection in the treatment of multidrug-resistant tuberculosis: A retrospective study of 56 cases. Ann Thorac Surg 2008; 86:1640-5.

10. Alan DL, Wing Wai. The current role of thoracic surgery in tuberculosis management. Respirology 2009; 14:954-68.

11. Ponerantz M. Surgical management of resistant mycobacterium tuberculosis. $J$ thoac Cardiovascular Surg 2001; 121:448.

12. Giorgio Zanotti MD, John D. Mitchell MD. Bronchopleural fistula and empyema after anatomic lung resection. Thorac Surg Clin 2015; 25:421-7.

13. Sihoe ADL, Shiraishi Y, Yew WW. The current role of thoracic surgery in tuberculosis management. Respirology 2009; 14: 954-68.

14. Deschamps C, Miller DL, Nichols FC, Parirolero PC. Management of post-pneumonectomy empyema and bronchopleural fistula. Semin Thorac Cardiovascular Surg 2001; 13:13-9.

15. Asamura H, Naruke T, Tsuchiya R, Goya T, Kondo H, Suemasu K. Bronchopleural fistulas associated with lung cancer operations. Univariate and multivariate analysis of risk factors, management, and outcome. J Thorac Cardiovasc Surg 1992; 104:1456-64.

16. Sonobe $M$, Nakagawa $M$, Ichinose $M$, Ikegami N, Nagasawa $N$, Shindo T. Analysis of risk factors in bronchopleural fistula after pulmonary resection for primary lung cancer. Eur JCardioThoracic Surg Vol. 18, 2000; 5:519-23.

17. Brik A, Salem AM, Saber O. Intercostal muscle flap in post tuberculous pneumonectomy: A new technique. Surg Sci 2012; 3:249-52.

18. Nelson KG, Griffith D, Wallace Jr RJ. Pulmonary mycobacterial disease: The role of surgical resection. Clin Pulm Med 2004; 11:355-62.

19. Kucharczuk JC, Kaiser LR. Resection of symptomatic, complex aspergilloma. 2007.

20. Chen QK, Jiang GN, Ding JA. Surgical treatment for pulmonary aspergilloma: A 35-year experience in the Chinese population. Interact Cardiovasc Thorac Surg 2012; 15:77-80.

21. Hankins JR, Miller JE, McLaughlin JS. The use of chest wall muscle flaps to close bronchopleural fistulas: Experience with 21 patients. Ann Thorac Surg 1978; 25:491-9. 